Chronic Obstructive Pulmonary Diseases:

Journal of the COPD Foundation

\author{
Letter to the Editor
}

\title{
Comments on "COPDGene 2019: Redefining the Diagnosis of Chronic Obstructive Pulmonary Disease"
}

\author{
Albert Miller, $\mathrm{MD}^{1,2,3}$ Lee K. Brown, $\mathrm{MD}^{4,5,6}$
}

\author{
Abbreviations: chronic obstructive pulmonary disease, COPD; computed tomography, CT; interstitial lung disease, ILD \\ Funding Support: not applicable \\ Citation: Miller A, Brown LK. Comments on "COPDGene 2019: redefining the diagnosis of chronic obstructive pulmonary disease." \\ Chronic Obstr Pulm Dis. 2020;7(2):79-81. doi: https://doi.org/10.15326/jcopdf.7.2.2020.0134
}

1 Division of Pulmonary, Critical Care and Sleep Medicine, Icahn School of Medicine at Mount Sinai, New York City, New York

2 Respiratory Institute-Mount Sinai Beth Israel Medical CenterNational Jewish, New York City, New York

3 Barry Commoner Center for Health and the Environment, Queens College, City University of New York, Queens

4 Division of Pulmonary, Critical Care and Sleep Medicine, Department of Internal Medicine, University of New Mexico School of Medicine, Albuquerque

5 Program in Sleep Medicine, University of New Mexico Health Sciences Center, Albuquerque,

6 Department of Electrical and Computer Engineering, University of New Mexico School of Engineering, Albuquerque

\section{Address correspondence to:}

Albert Miller, MD

Telephone: 718-670-4192

Email: almillermd@gmail.com

\section{Keywords:}

COPD; obstructive lung disease; CT emphysema

\section{To the Editor:}

The article, "COPDGene ${ }^{\circledR}$ 2019: Redefining the Diagnosis of Chronic Obstructive Pulmonary Disease" ${ }^{1}$ by the investigators in the COPD Genetic Epidemiology (COPDGene ${ }^{\circledR}$ ) study and published in a Special Issue of this journal in November, is welcomed by all (clinicians, epidemiologists, physiologists) in the pulmonary community for addressing the long vexing problem of identifying, among those at risk for COPD, the ones who will indeed progress to clinically and spirometrically-evident disease. The article presents 8 categories of patients evaluated for progression, all of whom were at risk because of "exposure considered positive," namely smoking at least 10 pack years. Unfortunately, former smokers were not distinguished from continuing smokers. Since the classic study of Fletcher and Peto $^{2}$ almost a half century ago, continuing smoking has been recognized as a major contributor to COPD progression.

Four of the 8 at-risk categories were defined by abnormal spirometry. There was no evidence of increased odds of progression for those with only abnormal spirometry or those with both abnormal spirometry and symptoms; the latter is unexpected since those with symptoms alone had an increased odds ratio of 1.41 . Perhaps this is an artifact of the classification; those with symptoms and abnormal spirometry had already progressed.

On the other hand, those with abnormal computed tomography (CT) alone had an odds ratio for progression of 1.31 which increased to 1.74 if symptoms were also present, to 2.11 if spirometry was abnormal and 2.82 if symptoms were present AND spirometry was abnormal. These findings certainly point to the importance of $\mathrm{CT}$ scans in evaluating the course of COPD. It is indeed fortunate that chest CTs are increasingly available to those at risk for COPD by virtue of their eligibility for screening because of their concomitant risk for lung cancer. It is incumbent on the screening radiologist to be attentive to the presence and extent of emphysema in these low-dose scans which do not include the expiratory views which were part of the COPDGene ${ }^{\circledR} 2019$ study. Such a broadening of their purview is consistent with attention to signs of parenchymal and/or pleural findings of 
pneumoconiosis, to evidence of interstitial lung disease and to extent of coronary artery calcification. This broadened attention to findings other than those indicative of lung cancer has been supported and now followed by one of the largest lung cancer screening consortia, the International Early Lung Cancer Action Program.

\section{Declaration of Interest}

The authors have no conflicts of interest to disclose. 


\section{References}

1. Lowe KE, Regan EA, Anzueto A, et al. COPDGene 2019: redefining the diagnosis of chronic obstructive pulmonary disease. Chronic Obstr Pulm Dis. 2019;6(5):384-399.

doi: http://doi.org/10.15326/jcopdf.6.5.2019.0149

2. Fletcher C, Peto R. The natural history of chronic airflow obstruction. Br Med J. 1977;1(6077):1645-1648.

doi: https://doi.org/10.1136/bmj.1.6077.1645 